\title{
Development of a Three-Dimensional Ray-Tracing Model of Sugarcane Canopy Photosynthesis and Its Application in Assessing Impacts of Varied Row Spacing
}

\author{
Yu Wang ${ }^{1,2}$ - Qingfeng Song ${ }^{1}$ - Deepak Jaiswal ${ }^{2}$ - Amanda P. de Souza ${ }^{2}$. \\ Stephen Patrick Long ${ }^{2,3,4} \cdot$ Xin-Guang $\mathrm{Zhu}^{1,2}$
}

Published online: 14 April 2017

(C) The Author(s) 2017. This article is an open access publication

\begin{abstract}
Sugarcane has emerged as the second largest source of biofuel, primarily as ethanol produced in Brazil. Dual row planting using asymmetric spacing of rows can decrease damage to plants and soil structure from harvest equipment though potentially can cause some loss of productivity due to increased shading. Can we assess this loss, without experimental testing of the thousands of potential permutations of planting design and cultivar canopy form? Here we develop a computational framework which couples 3D canopy architectural information, a ray-tracing algorithm, and a steady-state $\mathrm{C}_{4}$ photosynthesis model to study this question. We demonstrate the utility of the model by comparing evenly spaced rows at $100 \mathrm{~cm}$ to alternating row spacing of 45 and $155 \mathrm{~cm}$. Asymmetric planting caused a $9 \%$ decrease in predicted net canopy carbon uptake over the growing season for a major current cultivar. The loss was greater at lower leaf area indices,
\end{abstract}

Electronic supplementary material The online version of this article (doi:10.1007/s12155-017-9823-x) contains supplementary material, which is available to authorized users.

Stephen Patrick Long

slong@illinois.edu

$\triangle$ Xin-Guang Zhu

zhuxinguang@picb.ac.cn

1 CAS Key Laboratory of Computational Biology and CAS-MPG Partner Institute for Computational Biology, Shanghai Institutes for Biological Sciences, Chinese Academy of Sciences, 320 Yueyang Road, Shanghai 200031, China

2 Carl R. Woese Institute of Genomic Biology, University of Illinois, 1206 W Gregory Dr, Urbana, IL 61801, USA

3 Departments of Crop Sciences and of Plant Biology, University of Illinois, 1201 W Gregory Dr, Urbana, IL 61801, USA

4 Lancaster Environment Centre, Lancaster University, Lancaster LA1 4YQ, UK when leaves were more vertical and when rows were oriented east-west, suggesting agronomic approaches to minimize loss. This study demonstrates the utility of this computational framework, which could also be used to aid breeding by identifying ideotypes for different environments and objectives, and to assess impacts of environmental change.

Keywords Canopy photosynthesis · Bioenergy · Canopy architecture $\cdot$ Crop row orientation

\section{Introduction}

Sugarcane has emerged as the second largest source of biofuel and it has the potential in Brazil alone to provide $15 \%$ of global liquid fuel use in transportation [1]. Realizing its important potential for offsetting fossil fuel greenhouse gas (GHG) emissions requires continued improvement of its yield. In theory, the ideal planting arrangement for maximizing the potential yield of a crop is a regular arrangement so that plants are equidistant, that is the distance between plants within a row equals the distance between rows. For a given population density, this minimizes the time to canopy closure and maximizes light interception. However, any planting arrangement and row spacing has to be a compromise between the yield loss from a less than perfect arrangement for light capture, costs of planting, and practicalities of mechanized harvesting. For a perennial and high mass yielding crop such as sugarcane, this is particularly important since the risk of plant and soil damage is high from the necessarily heavy harvesting and haulage equipment. Therefore, row spacing and equipment choices need to minimize this damage by keeping their impacts away from the rows. This damage has been recognized in regions where mechanization has been in place for many years [2]. This is now a well-recognized issue for the world's largest sugarcane 
producing country, Brazil, as it completes its transition from manual to mechanized harvesting $[3,4]$.

Although planting is commonly at around 1 to $1.5 \mathrm{~m}$ rows in many growing regions, this is a poor match to harvesters and haulage trucks with wheel bases of $\geq 1.8 \mathrm{~m}$. The outcome of this mismatch is that wheels and tracks have to traverse rows damaging stools and compacting soil, with a measurable yield loss [5]. Additionally, harvesting is usually conducted with a single-row harvester. Therefore, the inter-row is traversed twice by the harvester and at least twice by the associated haulage truck. Matching row spacing with wheelbases to allow controlled traffic that avoids the rows allows maintenance of better soil physical properties and slows the decline in yields with the number of ratoons [5]. A slower decline will allow a longer time before a field needs to be replanted, so reducing both costs and inputs, while maintaining yields.

However, wider row spacing would decrease potential yield by slowing time to canopy closure. An alternative that does not have to decrease the planting density is to use asymmetric row spacing. For example, instead of $1 \mathrm{~m}$ spacing, a double row separated by $45 \mathrm{~cm}$, with the centers of the double row separated by $2 \mathrm{~m}$. These two designs would have the same population density and the same cost in terms of propagules planted per hectare. However, it has two practical benefits. First, the two rows can be harvested together, so halving the number of passes made by the harvester and by the haulage truck that collects the cut cane from the harvester and then carries it out of the field to the mill [6]. Secondly, the spacing will be a better match to wheelbases allowing confinement of wheels and tracks to the inter-row. This avoids damage to the stools and compaction of soil within the rows.

The theoretical downside of the asymmetric row spacing is that canopy closure will take longer, with some yield penalty, while there will be increased shading within the paired rows, relative to regularly spaced rows. When maintaining the same total number of rows across trial plots, a significant yield loss was found when $30 / 150 \mathrm{~cm}$ spacing was used, relative to $60 /$ $120 \mathrm{~cm}$ spacing [7]. It is likely that a decline in yield caused by poorer light interception is offset by decreased damage and soil compaction or that replication was insufficient to provide statistical proof of a small yield loss. Further, impact will also likely depend on the form of the sugarcane cultivar with more spreading forms that bear more horizontal leaves less affected than less spreading forms with more vertical leaves. As a result, there are many more combinations of spacing and cultivar than can be assessed in practice through field trials, to determine loss and means to mitigate loss caused by different asymmetric planting designs that would allow two row harvesting. Most photosynthetically driven crop production models assume a spatially random distribution of foliage in dealing with light interception, and cannot therefore deal with the regular spatial pattern of variation in light distribution in canopies that results from planting in rows. This is even the case for most widely used sugarcane production model DSSAT/Canegro [8]. Increased computational power and new algorithms have now allowed realistic representation of stems and leaves in 3D space, in turn allowing high-resolution dynamic definition of the highly heterogeneous radiation transfer and leaf energy balance within the 3D space containing the canopy [9]. The advent of GPU-based computing is beginning to allow the dynamics of such 3D structures to be represented rapidly [10]. Combining this with biochemical models of $\mathrm{C}_{4}$ photosynthesis [11] would allow prediction of carbon gain at each point in the canopy over every minute of the day. This allows quantification of the effects of row spacing, orientation, and plant-plant interference on daily carbon assimilation in a realistic manner that takes account of the asymmetry of radiation interception in row crops as well as heterogeneity within the canopy. It avoids the need for the highly generalized assumptions of light distribution in crop canopies used in earlier models. This provides a means to narrow the range of spacing for actual field evaluations to likely optimal arrangements that meet the practical needs of more efficient and sustainable mechanized harvesting. At the same time, its mechanistic basis allows identification of strategies to minimize loss of production potential due to asymmetric spacing, such as optimal row orientation and choice of plant form. Here we develop such a model and illustrate one application, that is quantifying the potential impact of asymmetric spacing on carbon gain for a sugarcane crop.

\section{Materials and Methods}

Simulating the effects of row spacing on carbon assimilation in sugarcane required a model of three components: (i) a 3D canopy architectural model; (ii) a forward ray-tracing algorithm; and (iii) a steady-state biochemical model of $\mathrm{C}_{4}$ photosynthesis. This requires season long data of stem numbers and arrangement, heights, points of leaf insertion, leaf angles, and their length and curvature. The data used for this calibration, and demonstration of the model, are those described for cultivar RB86-7515 growing at Embrapa Cerrados, Planaltina, DF, $15^{\circ} 39^{\prime} 84$ "S, 4744' 41 "E [12] (Tables S1 and S2). RB867515 was the most planted cultivar in Brazil in 2013 [13]. It corresponded to 24\% of the total sugarcane planted in Sao Paulo, Brazil, which produces the most sugarcane of all states in Brazil [13]. To account for leaf-to-leaf variation in size and curvature at any given node, a normal distribution was assumed with a standard deviation of $15 \mathrm{~cm}$ for leaf position, $9^{\circ}$ for leaf curvature, and $15^{\circ}$ for leaf direction. Using these distributions, leaves were generated within this population with mean values as given in Table S1. Three block-repeats of sugarcane canopy were generated for each simulated day. Calibration to this sugarcane cultivar provides the location 
of the stem and leaves within a $3 \mathrm{D}$ cube. Each leaf is divided into units of $\leq 2 \mathrm{~cm}^{2}$ area, containing information on its azimuth and zenith angles. Within each voxel occupied by a portion of leaf, the sum of the direct, diffuse, and scattered light incident is calculated for each hour of the passage of the sun across the sky, as described previously $[9,14]$. The coupled 3D canopy architecture model and forward ray-tracing algorithm developed for rice [14] was adapted here for sugarcane. Since the original model was developed for a tillering grass with sequential production of linear leaves on each tiller changes were only in parameterization; see [14] for a full description of the model. Although the cube simulated in this model is only a few rows and meters of length of rows, the simulation avoids over-estimation of light at the edge of the cube by allowing light that leaves one edge to re-enter at the opposite side so giving the effect of a cube surrounded by identical cubes of the same crop. This allows simulation of a whole field, with the assumption that the simulated adjacent cubes are identical. For the full equation set and model explanation, together with equation symbol and parameter definitions, see Supporting Information1 Sections 2-4. At each date, solar angle and the proportion of direct to diffuse radiation was calculated from date and the latitude at Planaltina, DF, and an assumed atmospheric transmittance of 0.85 . At each time point, this provides an estimate of incident photon flux at each unit of area (ca. $2 \mathrm{~cm}^{2}$ ) within every leaf borne on every stem within the cube. From this, the photosynthetic rate of $\mathrm{CO}_{2}$ uptake minus the rate of leaf respiration was calculated using the steady-state biochemical model of $\mathrm{C}_{4}$ photosynthesis of Collatz et al. [15] (Supporting Information1, Section 3).

The utility of the model was demonstrated with two different row spacing designs: symmetrical at $100 \mathrm{~cm}$ between each row and asymmetrical with dual rows separated by $45 \mathrm{~cm}$ centered at $200 \mathrm{~cm}$ spacing (Fig. 1). Both designs give an average row spacing of $100 \mathrm{~cm}$, and hence the same density of stems and leaves per unit ground area. Plant spacing was varied along with the growth based on the measured tiller number along each row (Table S1 and Table S2). Canopy structure was based on published measurements of RB867515 across the growing season, and simulations were conducted for each date on which measurements had been taken [12] (Table S1, Table S2). Although spacing would likely affect leaf area index (LAI) and vertical distribution of leaves, for simplicity and ease of interpretation it was assumed that LAI and architecture were the same at both spacings, such that only the effect of horizontal variation in the distribution of leaves and stems was assessed. For leaf photosynthesis, the parameters of the model of $\mathrm{C}_{4}$ photosynthesis [15] were set at $60 \mu \mathrm{mol} \mathrm{m} \mathrm{m}^{-2} \mathrm{~s}^{-1}$ for maximum rubisco activity $\left(V_{\max }\right)[16$, 17]. The initial slope of photosynthetic $\mathrm{CO}_{2}$ response $(k)$ and apparent maximum quantum yield $(\alpha)$ were set at $0.7 \mathrm{~mol} \mathrm{~m}^{-2} \mathrm{~s}^{-1}$ and 0.05 , respectively $[15,17]$. Leaf mitochondrial respiration $\left(R_{d}\right)$ was $0.01 V_{\max }$ [18]. These parameters were held constant for all simulations. Photosynthesis, calculated in $\mu \mathrm{mol} \mathrm{m} \mathrm{m}^{-2} \mathrm{~s}^{-1}$ was converted to biomass equivalent, assuming that $1 \mathrm{~mol}$ of $\mathrm{CO}_{2}$ assimilated would result in $30 \mathrm{~g}$ of carbohydrate. Carbohydrate mass gain was predicted over the whole growing season, assuming that $40 \%$ of photosynthate is

\section{Asymmetric planting}

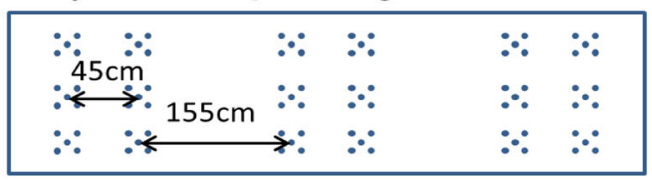

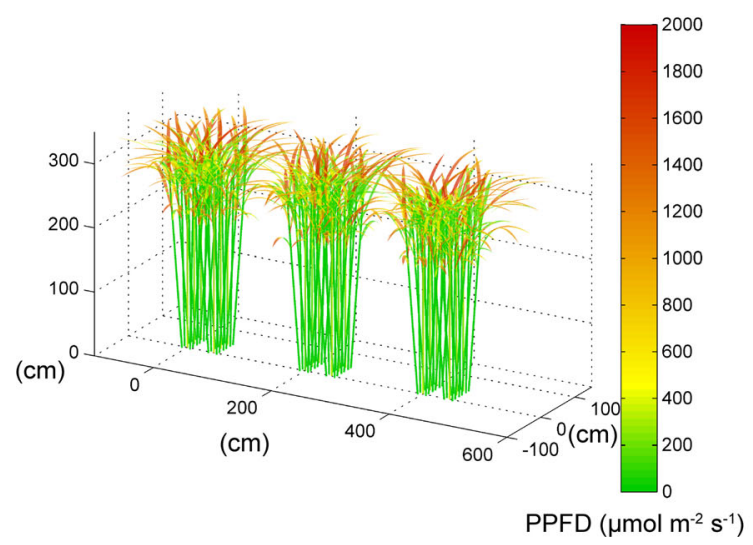

Fig. 1 Simulated sugarcane canopies with alternative row spacing. It was assumed that there were 25 stems per meter of row. Spacing of rows in the two simulated planting designs were; asymmetric, dual rows, on the left with alternating 155 and $45 \mathrm{~cm}$ spacing; and symmetric on the right with

\section{Symmetric planting}

\begin{tabular}{|c|c|c|c|}
\hline$\therefore$ & $\therefore:$ & $\therefore:$ & $\therefore \because$ \\
\hline$\because 100 \mathrm{~cm}^{\circ} \because 100 \mathrm{~cm}^{\circ} \because$ & $\because \because$ & $\because \because$ & $\because \because$ \\
\hline : \: & $\therefore$ & $\because \because$ & $\therefore$ \\
\hline
\end{tabular}

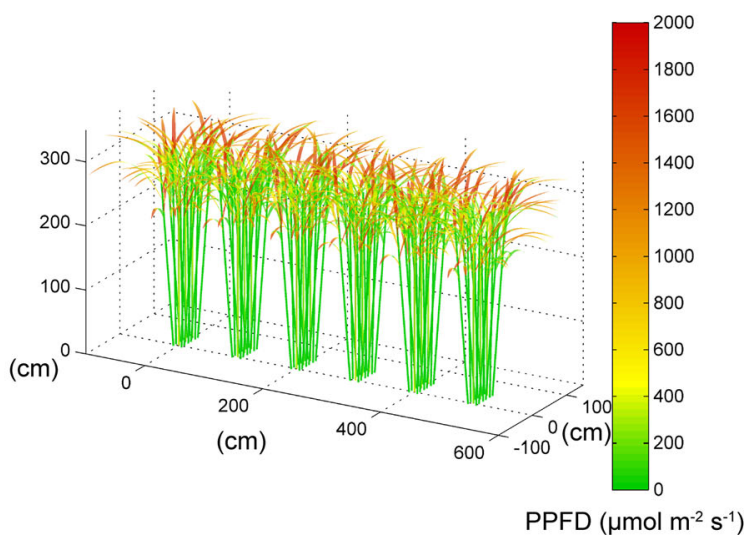

$100 \mathrm{~cm}$ spacing between all rows. Colors represent the light flux received at different points in the canopy at 9 am of March 23 at latitude $15^{\circ} 39^{\prime} 84$ "S. To see how the illustrated light distribution changes over a diurnal cycle see the animations in the online Supplementary Figs. S1-S4 
lost in whole-plant respiration [19, 20]. All simulations were conducted in MATLAB (R2014b, Mathworks Inc.)

Because each canopy is generated stochastically based on the measured field data and within the constraints outlined above, each is different and hence generating different results. The significance of differences in simulated carbon gain over the growing season production for different row spacings and row orientations were tested by repeated-measures ANOVA. Simulated diurnal net canopy $\mathrm{CO}_{2}$ uptake rates for different leaf angles, row spacings, and orientations were compared using unpaired Student's $t$ test, data are presented as mean \pm standard error. A $P$ value of 0.05 was considered significant. Analyses were performed using MATLAB (R2014b, Mathworks).

\section{Results}

The model was validated by comparing the predicted dry mass to earlier reported data of three individual cultivars from two publications $[21,22]$. Simulated dry mass, using the parameters for RB86-7515, SP83-2487, and RB72454 (Table S7), were comparable to measure data for the whole growing season [21, 22] (Fig. 2, Table S9). Linear regressions of simulated and measured dry mass for three cultivars indicate that the regression coefficients and $R^{2}$ are all close to 1 (Fig. 2).

The model allows dynamic representation of light environments of all elements in a realistic sugarcane canopy to a high resolution over a diurnal cycle (Fig. 1), which can be seen most
Fig. 2 Validation of the 3D sugarcane canopy model by comparing the simulated dry mass to the earlier reported dry mass for three cultivars. For each cultivar, we show both the changes of dry mass along the growth dates $(\mathbf{a}, \mathbf{c}$ e) and also the direct comparison between simulated and measured dry mass (b, d, f). a, b RB867515; c, d SP83-2487; e, f SP832487. The measured data used for comparison were from (Arantes, 2012 for a, b; Suiguitani, 2006 for $\mathbf{c}, \mathbf{d}, \mathbf{e}, \mathbf{f})$. The RMSE for $\mathbf{a}, \mathbf{c}, \mathbf{e}$ are $22.80,5.89$, and 14.63 , respectively
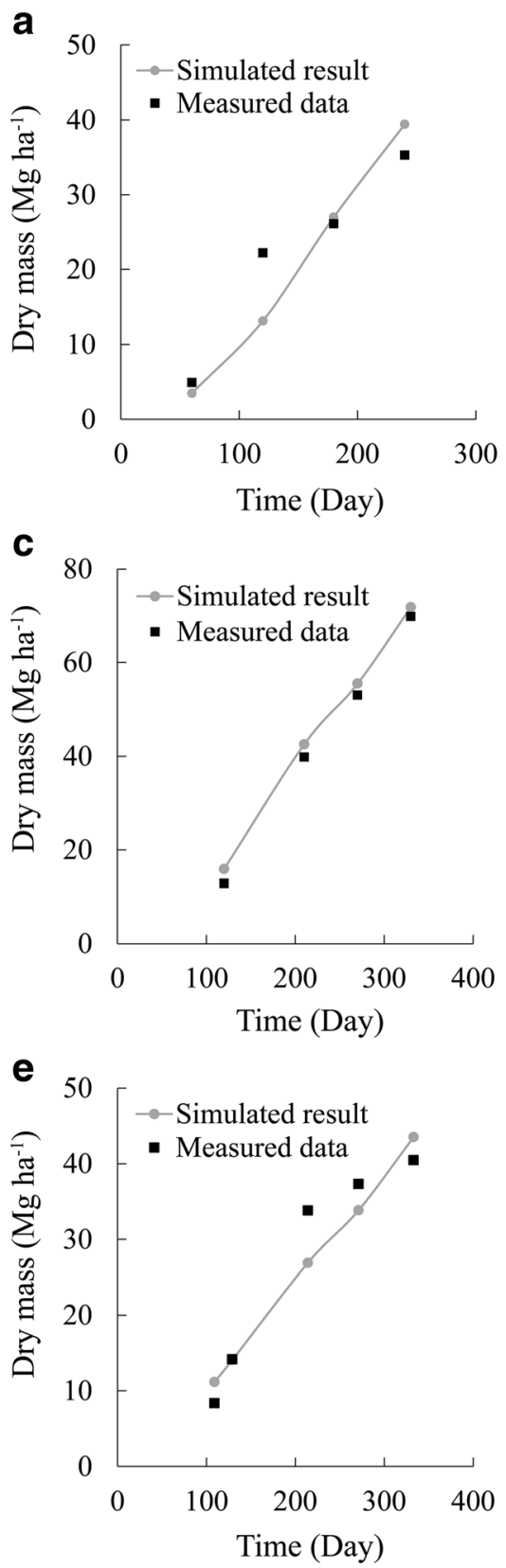

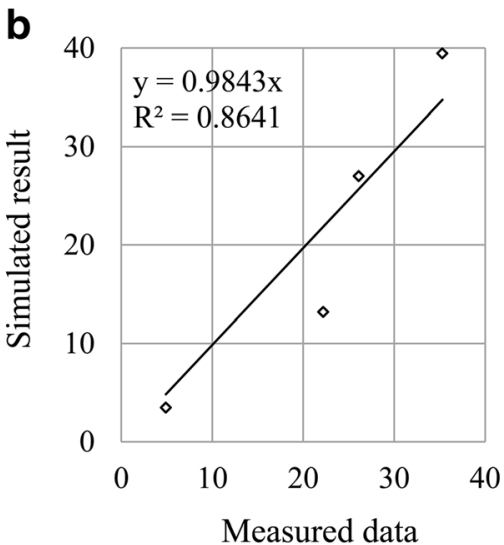

d

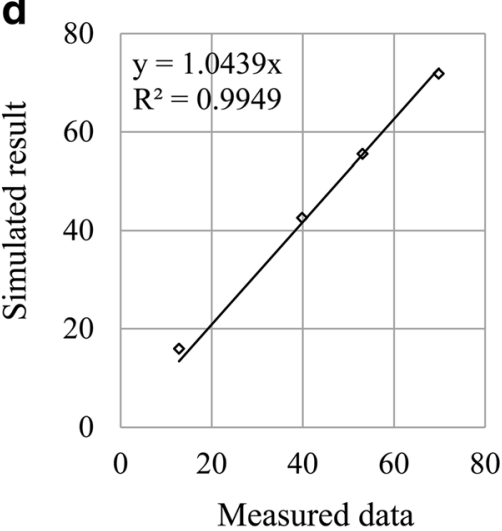

f

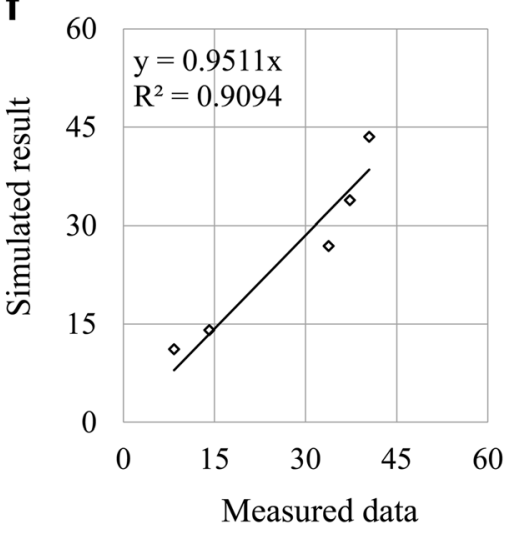


clearly in the animations provided in the Supplementary information (Figs. S1-S4). Representation of the morphological data into the 3D canopy model shows that even at the $1.55 \mathrm{~m}$ spacing between two rows, leaves from these two rows begin to touch by February although clearly with more gaps in the asymmetric spacing (Fig. 1). Predicted net daily canopy carbon gain is shown for each month of the year in Fig. 3, Table S4, which shows a lower simulated net carbon gain for asymmetric row spacing which is most pronounced with east-west row orientation. Examining the diurnal cycle of the 326th day after last harvest (15th October), for a high LAI (6.6) the asymmetry results in a loss of $3.4 \%$ of daily biomass gain for east to west rows, but this loss can be reduced to $1.3 \%$ by planting rows in a north to south orientation (Fig. 4, Table S5). This is most marked around mid-day (Fig. 4a). The losses are greater in crops and cultivars with a lower LAI (4.6), i.e., they became $8.1 \%$ for E-W rows and $4.7 \%$ for N-S rows (Fig. 4b, Table S5). The cultivar illustrated has relatively upright leaves (Fig. 1). Cultivars with larger angles relative to the stem, i.e., more horizontal leaves, will spread more rapidly to fill the larger gap between the rows (Fig. 1). This also serves to demonstrate the utility of the model in accommodating plasticity, in this case in leaf angles. For a LAI of 5.6, N-S rows, the loss for a more erect canopy of leaf angle $15^{\circ}$ due to the asymmetric arrangement of rows was $5.1 \%$, but only $1.0 \%$ with a leaf angle of $45^{\circ}$ on 326 th day (Fig. 5, Table S6).

On the 167 th day, when LAI was 5.5 , the asymmetry resulted in a loss of $15.2 \%$ of daily carbon gain for the E-W

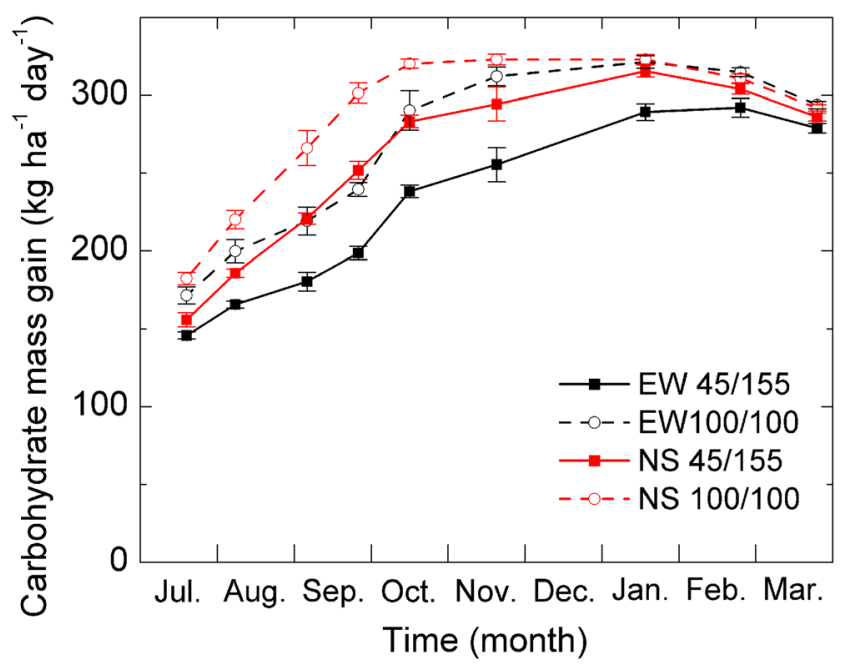

Fig. 3 Simulated net canopy carbon uptake for a sugarcane plant crop over the whole growing season for symmetric and asymmetric spacing arranged in east-west (E-W) and in north-south (N-S) rows. 45/155 represents asymmetric planting with alternating 155 and $45 \mathrm{~cm}$ spacing; $100 / 100$ represents symmetric planting with $100 \mathrm{~cm}$ spacing between all rows. Atmospheric transmittance was set as 0.85 , as in all simulations. Repeated-measures ANOVA: $P<0.001$, for asymmetric planting compared to symmetric planting in both $\mathrm{E}-\mathrm{W}$ and N-S rows; unpaired $t$ test: $P<0.001$, for $\mathrm{E}-\mathrm{W}$ versus $\mathrm{N}-\mathrm{S}$ rows in asymmetric planting; $P=0.0014, \mathrm{E}-\mathrm{W}$ versus N-S rows in symmetric planting rows, and $9.4 \%$ for N-S rows. For a low LAI (3.4) on this date, the asymmetry resulted in a loss of $21.9 \%$ for the E-W rows and $14.6 \%$ for the N-S rows (Fig. 6, Table S5). This shows higher canopy carbon uptake for N-S rows on both the 167th and 326th day (Fig. 6, Table S5). To evaluate which direction would give higher productivity over the whole growing season, we simulated the net canopy carbon uptake of sugarcane for each month of the growing season (Fig.3). For asymmetry planting, an E-W orientation of rows decreased the integrated net canopy carbon uptake $10.1 \%$ compared to N-S. Given N-S orientation of rows, dual row planting with alternative row spacing of 45 and $155 \mathrm{~cm}$ decreased net canopy carbon uptake by $8.7 \%$ across the full growing season. While the loss of carbon uptake increases to $13.2 \%$ if row orientation is E-W (Fig. 3, Table S4, Supporting Information2).

\section{Discussion}

The model presented here is parameterized on a major current commercial production clone. For the asymmetric spacing which allows dual row harvesting, the model predicts a daily crop photosynthetic gain of about $406 \mathrm{~kg} \mathrm{ha}^{-1}$ day $^{-1}$ of carbohydrate mass averaged across the growing season of 11 months (337 days) simulated here. Assuming that ca. $40 \%$ of this photosynthate is lost in respiration for cell maintenance and metabolism to other plant constituents [5, 6], this would equate to a total dry matter productivity of about $82 \mathrm{mg} \mathrm{ha}^{-1}$ year $^{-1}$ (243 $\mathrm{kg} \mathrm{ha}^{-1}$ day $^{-1}$ ) (Fig. 3, Supporting Information 1 Sections 5). How does this compare to actual yields? The average yield of harvested stem in Brazil is about $80 \mathrm{mg} \mathrm{ha}^{-1}$ year $^{-1}$ [23]. However, this is wet weight, of which only $30-40 \%$ is dry mass [24-26]; harvest index is about $50 \%$, with the unharvested material being leaf litter, stem tops, and root $[8,27])$, therefore total dry matter production would be about 48-64 mg ha ${ }^{-1}$ year ${ }^{-1}$. Since our row spacing simulations are based on the measurements from the first year ratoon crop, simulated dry matter productivity is higher than the average. The simulated dry matter yields of the first year plant for model validation are from 43.5 to $71.8 \mathrm{mg} \mathrm{ha}^{-1}$ year $^{-1}$ (Fig. 2c, e, Table S9), which are comparable to measured data and the dry matter calculated from the average yield in Brazil [23]. It should be noted that the row spacings chosen here were simply to demonstrate the utility of the model in dealing with agronomic and varietal questions; these were not intended to represent spacings used in any particular growing region. As noted later, although production is predicted here, the canopy model developed is intended as a more effective front-end to more detailed production models, in the context of questions such as row spacing and orientation at different locations and with different cultivars.

This study suggests that under the climatic conditions of cultivation in Planaltina, Goiás state, dual row versus regular 
Fig. 4 The predicted diurnal net canopy $\mathrm{CO}_{2}$ uptake rate $\left(A_{c}\right)$ on March 23 (326th day). 45/155 represents asymmetric planting with alternating 155 and $45 \mathrm{~cm}$ spacing; 100/100 represents symmetric planting with $100 \mathrm{~cm}$ spacing between all rows for high and low leaf area indices (LAI). Points represent the mean and \pm standard error, where $*=P<0.05$ and $* *=P<0.01$ (unpaired $t$ test). a For E-W rows, the asymmetry results in a loss of $8.1 \%$ for low LAI (4.6) and 3.4\% for high LAI (6.6); $\mathbf{b}$ for N-S rows, the asymmetry results in a loss of $4.7 \%$ for low LAI (4.6) and $1.3 \%$ for high LAI (6.6). The simulated daily total canopy photosynthetic $\mathrm{CO}_{2}$ uptake rates for these different scenarios are shown in Table S5 a
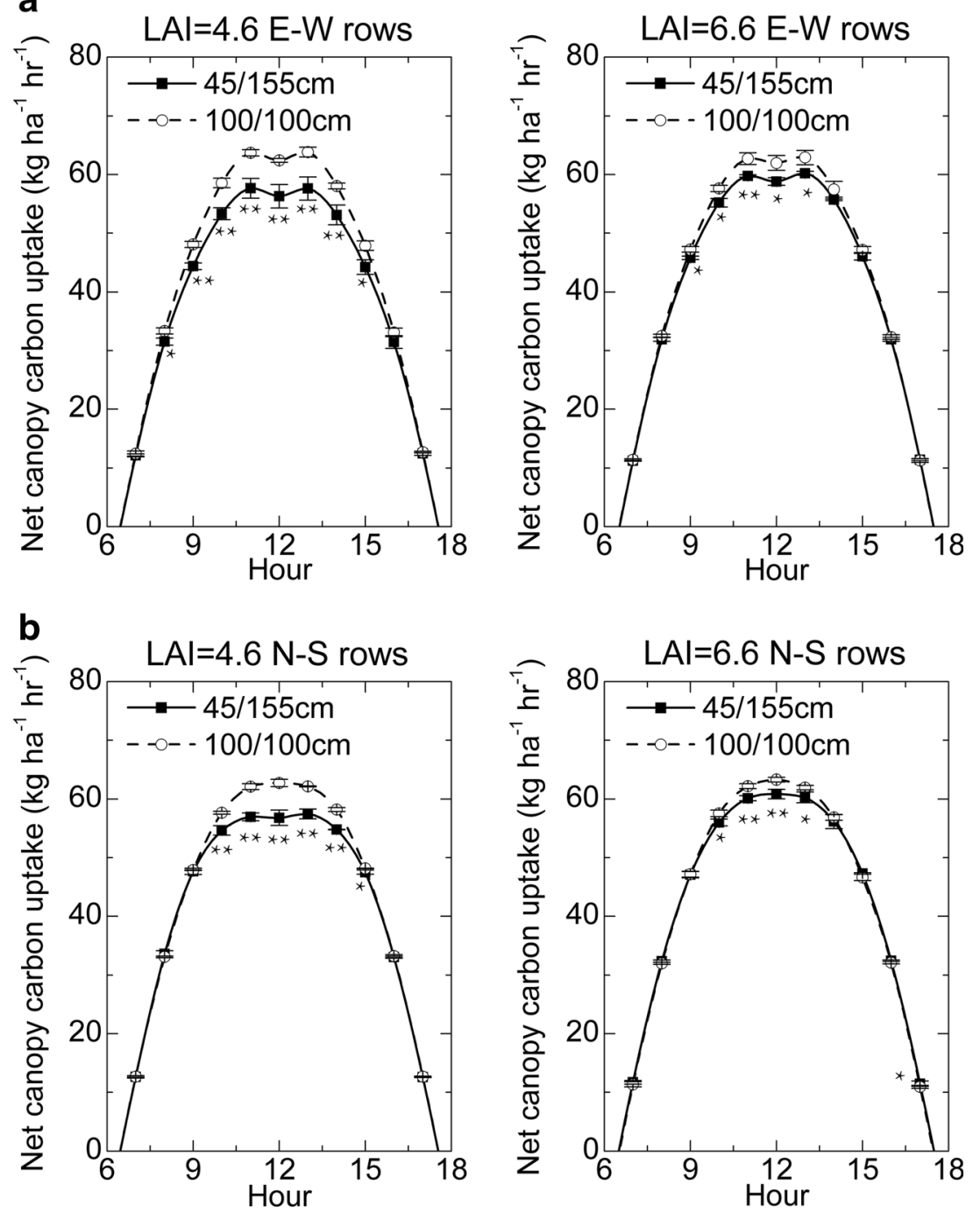

row planting would have little effect on crop carbon gain, after canopy closure. The loss would be most severe in cultivars with upright leaves and could be largely mitigated by selecting cultivars with a more spreading habit, i.e., more horizontal
Fig. 5 The effect of low and high leaf angle on diurnal net canopy $\mathrm{CO}_{2}$ uptake rate $\left(A_{c}\right) .45 / 155$ and $100 / 100$ represent asymmetric and symmetric row spacing, respectively. LAI was set as 5.6. The date is March 23 (326 days after planting). $*=P<0.05$ and $* *=P<0.01$ (unpaired $t$ test). For N-S rows, the loss for leaf angle $15^{\circ}$ due to the asymmetric arrangement of rows was $5 \%$, but only $1 \%$ with a leaf angle of $45^{\circ}$. The simulated daily total canopy photosynthetic $\mathrm{CO}_{2}$ uptake rates for these different scenarios are shown in Table S6
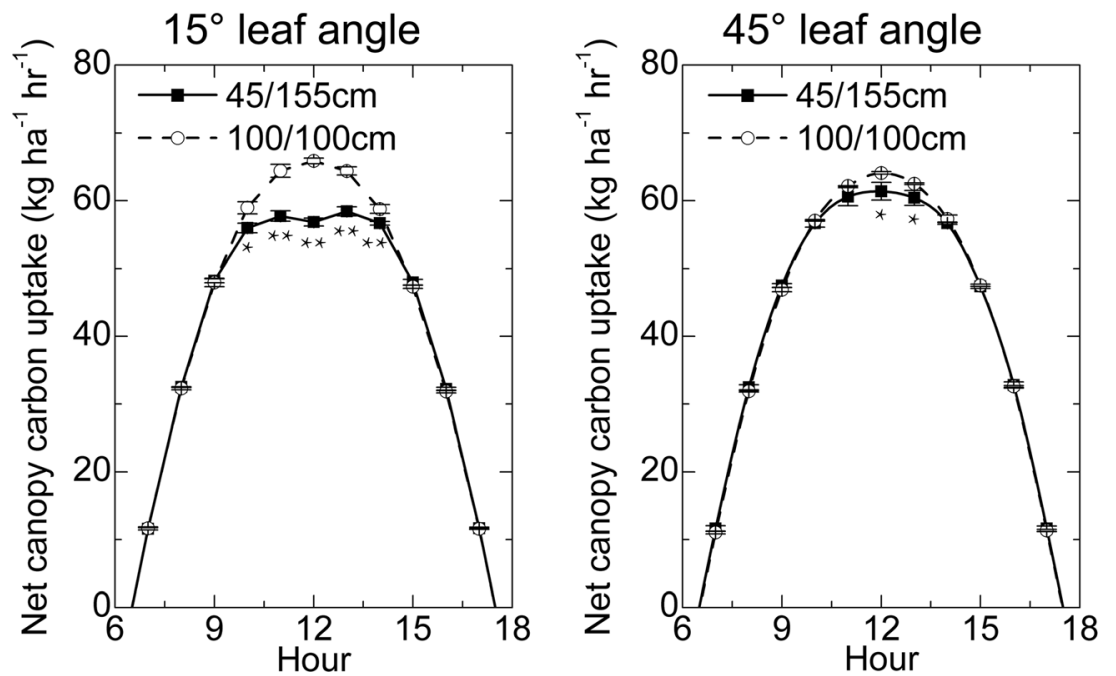
Fig. 6 The diurnal canopy $\mathrm{CO}_{2}$ uptake rate $\left(A_{c}\right)$ on October 15 th (167 days after planting), 45/155 represents asymmetric rows and $100 / 100$ symmetric. $*=P<0.05$ and $* *=P<0.01$ (unpaired $t$ test). a E-W rows, the asymmetry resulted in a loss of $21.9 \%$ of daily carbon gain for low LAI (3.4) and $15.2 \%$ for high LAI (5.5); b N-S rows, the asymmetry resulted in a loss of $14.6 \%$ for low LAI (3.4) and 9.4\% in high LAI (5.5). The simulated daily total canopy photosynthetic $\mathrm{CO}_{2}$ uptake rates for these different scenarios are shown in Table S5
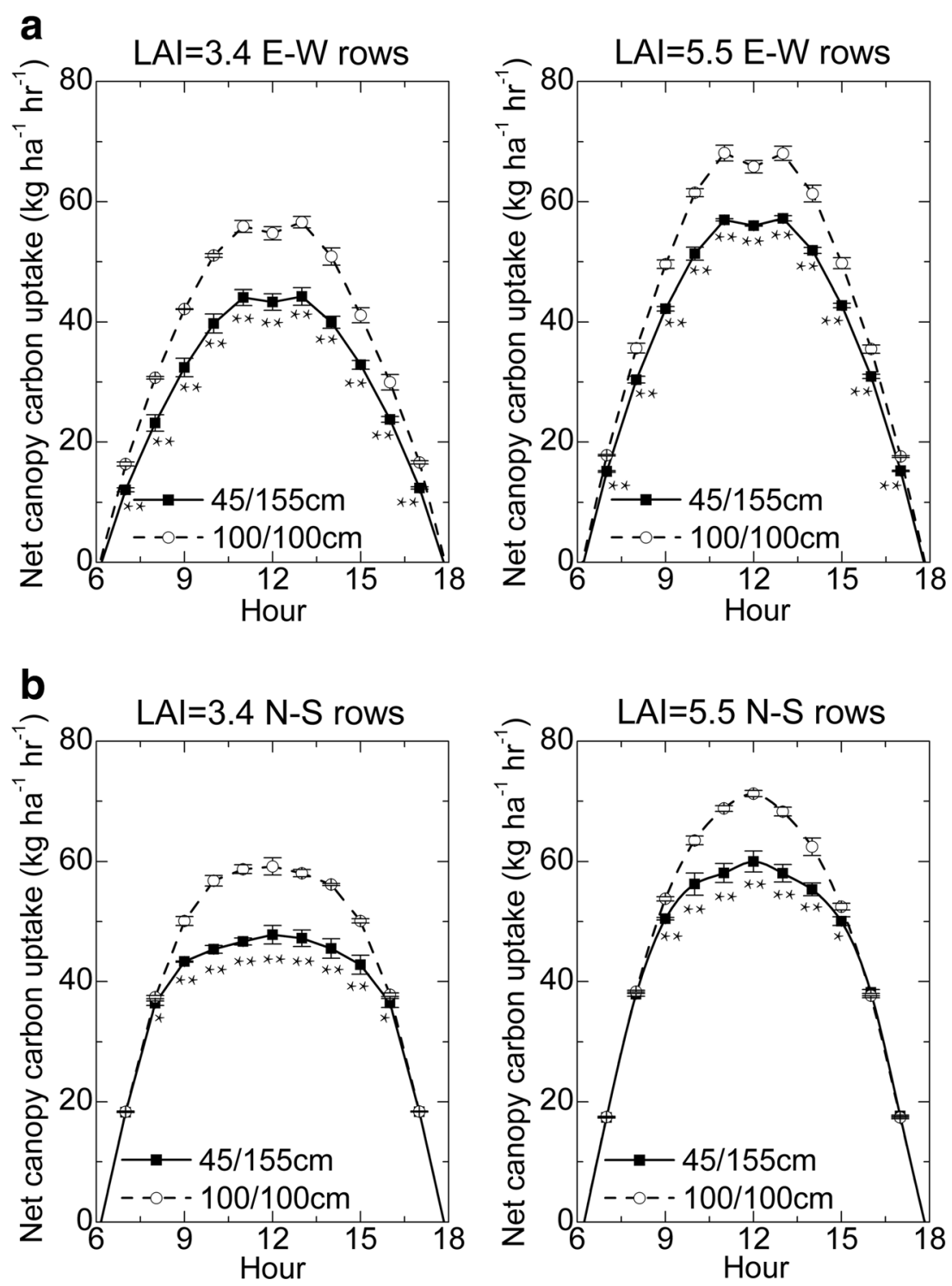

leaf, and by planting in an N-S orientation area (Figs. 3-6). E$\mathrm{W}$ versus N-S orientation of rows has more significant effect on carbon gain with asymmetrical row spacing (Fig. 3). Compared to E-W rows, using a N-S row orientation with dual row planting would increase the projected harvested stem yield $8 \mathrm{mg} \mathrm{ha}^{-1}$ year $^{-1}$, which could increase sugar production about $2 \mathrm{mg} \mathrm{ha}^{-1}$ year $^{-1}$, assuming that sucrose is $50 \%$ of harvested stem dry mass [27, 28]. Given an ethanol yield of 86.3 L mg (cane $)^{-1}$ [29], ethanol production would be increased by $690 \mathrm{~L} \mathrm{ha}^{-1}$ year ${ }^{-1}$.

However, simulated losses due to dual row spacing may be underestimated. Over the whole cycle, the effect of asymmetric spacing is profound during the first months of growth, when the rows result in substantial areas of bare ground, and therefore light that is not intercepted by the crop (Fig. 3). This example simulation assumes that LAI is unaffected by poorer productivity in the asymmetric row spacing. If lower productivity results in lower leaf area production, losses will be compounded with time. Agronomically, this loss would be partially mitigated by planting rows in an N-S orientation or use of cultivars with more horizontal leaf angles (Fig. 3). Since the $155-\mathrm{cm}$ gap between the edges of the dual planted rows is never fully closed, it will result in significantly lower solar radiation interception.

The model assumes that all the plants are in well-watered and sufficient nutrient conditions, so that the potential changes of root system in dual row planting are not taken into account in this study. The model also takes no account of the benefit that dual rows would bring in decreasing traffic and damage to rows, which might offset even the $7.5-11 \%$ loss in potential canopy photosynthetic biomass gain predicted here. The model also assumes that plant structure is unaltered by dual row planting. In reality, two factors could act to modify the outcome here. First, plants sense neighbors via phytochromes, 
which elicit responses in increasing height and seeking gaps in the canopy [8]. Increasing height may consume more energy in stem structure, while seeking more light could compensate to some extent for the increased shading interference produced by dual rows. Salter et al. [30] show row space, has little effect on sugarcane yield, which indicates the growth plasticity of sugarcane could even further reduce the loss of dual row. Our simulation shows that, on day 326 , if the leaf angle of the dual row planting was increased from $15^{\circ}$ to $45^{\circ}$, the potential loss of daily total carbon uptake was decreased from 5 to $1 \%$, and the loss decreased from 16 to $8.5 \%$ on the 167th day in northsouth rows (Fig. 5 and Fig. S5), which suggests that seeking more light and hence more horizontal leaves in dual row planting could halve the loss that would otherwise occur. As a proxy for plasticity, this shows that where a cultivar responds to the wider spacing by producing more horizontal leaves, the yield loss effects of asymmetry will be diminished.

The current simulations were developed to illustrate the potential of this new modeling tool (Supporting Information 1 Sections 2 and 3) for sugarcane agronomy and clone selection, since it can simulate realistic 3D crop canopies for in silico experimentation. One limitation here is that an early small effect of productivity may propagate to larger effects through compound interest during exponential growth and hence greatly affect final yields. Any such effect is not represented here. However, in the future this could be achieved by combining the canopy description and photosynthesis model developed here with crop growth and production models such as BioCro [11] or DSSAT/Canegro [8]. The framework to use such canopy representation for every day of the growth cycle of a crop is presented. However, the current model is limited to running MATLAB on CPU architecture, which makes execution of such a detailed representation of canopy microclimate relatively slow [9]. In the future, the computational simplicity of what is represented in each pixel of the 3D space would allow use of emerging parallel GPU architecture. This could speed computation by $1-3$ orders of magnitude $[10,31]$.

This study provides the framework of a new computational approach, which could be used to evaluate the cost-benefit of different combinations of row spacing to fit both field equipment dimensions and cultivar forms in different locations. In effect it enables analysis of genotype $\mathrm{x}$ environment $\mathrm{x}$ management (GxExM). It brings potential for a closer link between field agronomy and modeling by allowing investigation of multiple permutations of population density, row spacing, row orientation, and cultivar selections, for example. As such, it allows prediction of the best combinations, in theory, for actual field testing. As shown here, the model can also be used to predict the form of cultivar that might be best suited to a given agronomy. The model could be combined with an evolutionary algorithm or other optimization routine to predict the ideotypes of sugarcane that would be best suited to dual row spacing or other variation in agronomy for a given climate zone. This would aid cultivar selection for a given situation and agronomy. Distances between stools, as another factor influencing sugarcane yield, could also be optimized by model prediction for higher productivity. While the model cannot replace agronomic field experiments, it provides a means to experiment with many more possibilities in silico to narrow down to the most promising strategy for field testing.

Acknowledgements This work was supported by the Energy Bioscience Institute, the Realizing Increased Photosynthetic Efficiency project of the Bill \& Melinda Gates Foundation, and the Chinese Academy of Sciences, including a Visiting Professorship to SPL and "Designer Breeding Molecular Module" to XGZ (XDA08020301).

Open Access This article is distributed under the terms of the Creative Commons Attribution 4.0 International License (http:// creativecommons.org/licenses/by/4.0/), which permits unrestricted use, distribution, and reproduction in any medium, provided you give appropriate credit to the original author(s) and the source, provide a link to the Creative Commons license, and indicate if changes were made.

\section{References}

1. Somerville C, Youngs H, Taylor C, Davis SC, Long SP (2010) Feedstocks for lignocellulosic biofuels. Science, 329, 790-792.

2. Braunack MV, Arvidsson J, Hakansson I (2006) Effect of harvest traffic position on soil conditions and sugarcane (Saccharum officinarum) response to environmental conditions in Queensland, Australia. Soil Tillage Res 89:103-121

3. Lozano N, Rolim MM, Oliveira VS, Tavares UE, Pedrosa EMR (2013) Evaluation of soil compaction by modeling field vehicle traffic with SoilFlex during sugarcane harvest. Soil Tillage Res 129:61-68

4. Torres JLR, Pereira MG, Cunha MA, Martins ME, DMdS V (2013) Physicochemical properties of soil and biomass in sugarcane harvesting systems. Revista de Ciencias Agrarias / Amazonian Journal of Agricultural and Environmental Sciences 56:311-318

5. Braunack MV, McGarry D (2006) Traffic control and tillage strategies for harvesting and planting of sugarcane (Saccharum officinarum) in Australia. Soil Tillage Res 89:86-102

6. Salassi ME, Champagne LP (1998) A spreadsheet-based cost model for sugarcane harvesting systems. Comput Electron Agric 20:215-227

7. Sreelatha T, Lakshmi CSR, Sireesha A, Rani TU, Ankaiah R (2013) Soil and crop productivity of sugarcane under different paired row spacings. Cooperative Sugar 44:47-50

8. Marin FR, Jones JW, Royce F, Suguitani C, Donzeli JL, Pallone WJ, Nassif DSP (2011) Parameterization and evaluation of predictions of DSSAT/CANEGRO for Brazilian sugarcane. Agron J 103:304-315

9. Song Q, Zhu X-G (2012) A model of canopy photosynthesis in rice that combines sub-models of 3D plant architecture, radiation transfer, leaf energy balance and $\mathrm{C} 3$ photosynthesis. Plant Growth Modeling, Simulation, Visualization and Applications. IEEE, 4, 360-366.

10. Owens JD, Houston M, Luebke D, Green S, Stone JE, Phillips JC (2008) GPU computing. Proceedings of the IEEE, 96, 879-899

11. Miguez FE, Zhu X, Humphries S, Bollero GA, Long SP (2009) A semimechanistic model predicting the growth and production of the bioenergy crop Miscanthus x giganteus: description, parameterization and validation. Global Change Biology Bioenergy 1:282-296

12. Batista LMT (2013) Avaliação morfofisiológica da cana-de-açúcar sob diferentes regimes hídricos. xix, 125 f., il. Dissertação (Mestrado em Agronomia) - Universidade de Brasília, Brasília, 125pp. 
13. Centro de Tecnologia Canvaieira (CTC) (2012) Censo Varietal, 18 http://www.ctcanavieira.com.br/site/images/downloads/censo ctc.pdf

14. Song Q, Zhang G, Zhu X-G (2013) Optimal crop canopy architecture to maximise canopy photosynthetic $\mathrm{CO} 2$ uptake under elevated $\mathrm{CO}_{2}$ - a theoretical study using a mechanistic model of canopy photosynthesis. Funct Plant Biol 40:109-124

15. Collatz GJ, Ribas-Carbo M, Berry JA (1992) Coupled photosynthesis-stomatal conductance model for leaves of $\mathrm{C} 4$ plants. Funct Plant Biol 19:519-538

16. Du YC, Kawamitsu Y, Nose A, Hiyane S, Murayama S, Wasano K, Uchida Y (1996) Effects of water stress on carbon exchange rate and activities of photosynthetic enzymes in leaves of sugarcane (Saccharum sp.) Funct Plant Biol 23:719-726

17. Meinzer FC, Zhu J (1998) Nitrogen stress reduces the efficiency of the $\mathrm{C} 4 \mathrm{CO} 2$ concentrating system, and therefore quantum yield, in Saccharum (sugarcane) species. J Exp Bot 49:1227-1234

18. von Caemmerer S (2000) Modeling of C4 photosynthesis. Biochemical models of leaf photosynthesis. CSIRO Publishing, Collingwood, pp 91-122

19. Gifford RM (1995) Whole plant respiration and photosynthesis of wheat under increased $\mathrm{CO}_{2}$ concentration and temperature: longterm vs short-term distinctions for modelling. Glob Chang Biol 1: 385-396

20. Wittig VE, Bernacchi CJ, Zhu XG, Calfapietra C, Ceulemans R, Deangelis P, Gielen B, Miglietta F, Morgan PB, Long SP (2005) Gross primary production is stimulated for three Populus species grown under free-air $\mathrm{CO} 2$ enrichment from planting through canopy closure. Glob Chang Biol 11:644-656

21. Arantes, MT (2012) Potencial produtivo de cultivares de cana-deaçúcar sob os manejos irrigado e sequeiro. 2012. (, Dissertação (Mestrado em Agronomia-Área de Concentração em Agricultura)-Faculdade de Ciências Agronômicas, Universidade Estadual Paulista, Botucatu), 65pp.
22. Suguitani, C (2006) Entendendo o crescimento e produção da cana de açúcar: avaliação do modelo Mosicas (Doctoral dissertation, Escola Superior de Agricultura "Luiz de Queiroz"), 60pp.

23. Goes T, Marra R, Araújo, M Alves E, Souza, MO (2011) Sugarcane in Brazil: current technologic stage and perspectives, Politica Agricola, January-March, 52-65. http://ainfo.cnptia.embrapa.br/ digital/bitstream/item/80803/1/Sugarcane-in-Brazil-currentetechnologic-stage-f.pdf

24. Bull TA, Glasziou KT (1975) Sugarcane.L.T. Evans (Ed.), Crop Physiology: Some Case Histories, Cambridge University Press, Cambridge , 51-72.

25. Bull TA, Glasziou KT (1963) The evolutionary significance of sugar accumulation in Saccharum. Aust J Biol Sci 16:737-742

26. Wu L, Birch RG (2007) Doubled sugar content in sugarcane plants modified to produce a sucrose isomer. Plant Biotechnol J 5:109 117

27. Singels A, Donaldson RA, Smit MA (2005) Improving biomass production and partitioning in sugarcane: theory and practice. Field Crop Res 92:291-303

28. Inman-Bamber NG, Muchow RC, Robertson MJ (2002) Dry matter partitioning of sugarcane in Australia and South Africa. Field Crop Res 76:71-84

29. Macedo IC, Seabra JE, Silva JE (2008) Green house gases emissions in the production and use of ethanol from sugarcane in Brazil: the 2005/2006 averages and a prediction for 2020. Biomass Bioenergy 32:582-595

30. Salter B, Garside AL, Berding N, Perna J, Park G (2012) Are genotype by row configuration interactions of consequence in cultivar development for wide row production? International Sugar Journal 114:183

31. Xu F, Mueller K (2005) Accelerating popular tomographic reconstruction algorithms on commodity PC graphics hardware. IEEE Trans Nucl Sci 52:654-663 